\title{
SOBRE EL DOCUMENTO DE PRÓSPERO CASOLA (1565-1647). PRIMER MANUAL SOBRE CONSTRUCCIÓN PERSPECTIVA CONOCIDO EN LAS ISLAS CANARIAS, DEL INGENIERO PRÓSPERO CASOLA
}

\author{
ABOUT THE DOCUMENT OF PROSPERO CASOLA (1565-1647). FIRST \\ TEXTBOOK ABOUT PERSPECTIVE CONSTRUCTION EVER KNOWN \\ IN THE CANARY ISLANDS, WRITTEN BY THE ENGINEER PROSPERO \\ CASOLA
}
Enrique Solana Suárez*, Manuel Lobo Cabrera ${ }^{* *}$, Elsa Gutiérrez Labory ${ }^{* * *}$ y Fernando Bruquetas de Castro ${ }^{* * * *}$

Fecha de recepción: 4 de septiembre de 2018
Fecha de aceptación: 25 de marzo de 2019

Cómo citar este artículo/Citation: Enrique Solana Suárez, Manuel Lobo Cabrera, Elsa Gutiérrez Labory y Fernando Bruquetas Castro (2019). Sobre el documento de Próspero Casola (1565-1647). Primer manual sobre construcción perspectiva conocido en las islas Canarias, del ingeniero Próspero Casola. Anuario de Estudios Atlánticos, n ${ }^{\circ}$ 66: 066-016.

http://anuariosatlanticos.casadecolon.com/index.php/aea/article/view/10549/9918

\begin{abstract}
Resumen: Este artículo es registro de manuscrito inédito de Próspero de Casola, hallado en el Archivo de la Casa Condal de la Vega Grande en Las Palmas GC. Necesaria la paleografía para transcribirlos. Ingeniero italiano fue técnico solvente en las fortificaciones de Canarias; padeció los ataques contra aquella ciudad por los piratas Drake (1595) y Van der Does (1599). Comunicaba personal y directamente con el rey, Felipe I, II y IV, prerrogativa de los ingenieros de la Monarquía, envía cartas continuamente a los monarcas con necesidades de las fortificaciones canarias. Manual aprendizaje de construcción perspectiva, facilitamos transcripción y orden, conteniendo dos grupos, agrupados incorrectamente, afinando la paleografía. El más interesantes realizado en su época en Canarias, y el primero en su tipo. Su finalidad, enseñar a hijo mayor sucesor ingeniero real en Canarias previsto, pero su muerte prematura hace se disponga para formar otros en esta ciencia.
\end{abstract}

Palabras claves: Fortificaciones, Perspectivas, Paleografía, Manuscritos, Canarias, Historia.

\begin{abstract}
This paper provides a log on the findings obtained from the study of the inedited handwritten text of Prospero Casola, found in the archives of Casa Condal de la Vega Grande, in Las Palmas de Gran Canaria. A paleographic analysis was necessary in order to transcribe the text. The Italian engineer was a knowledgeable technician specialized in Canary strongholds; he experienced first-hand the attacks against the city of Las Palmas de G.C. by the pirates Drake (1595) and Van der Does (1599). He had direct and personal communication with the kings Felipe I, II, and IV, as the engineers had the prerogative to directly notify the needs of such strongholds. A transcription and re-ordering of the textbook is provided,

* Profesor Titular en la Universidad de Las Palmas de Gran Canaria. Escuela de Arquitectura. Campus de Tafira. Las Palmas de Gran Canaria. España. Teléfono: +34.629148991; correo electrónico: enrique.solana@ulpgc.es

** Catedrático Universidad en Las Palmas de Gran Canaria. Edificio de Humanidades. Campus del Obelisco. Las Palmas de Gran Canaria. España. Correo electrónico: manuel.lobo@ulpgc.es

*** Profesora Contratada Doctora Escuela de Arquitectura. Universidad de Las Palmas de Gran Canaria. Campus Tafira. Las Palmas de Gran Canaria. España. Correo electrónico: elsa.gutierrez@ulpgc.es

**** Profesor Titular de la Universidad de Las Palmas de Gran Canaria. Edificio de Humanidades. Campus del Obelisco. Las Palmas de Gran Canaria. España. Correo electrónico: fernando.bruquetas@ulpgc.es
\end{abstract}


as it was found that the placing of some pages had been incorrectly swapped. This construction perspective handbook is the first of its kind in the Canaries, and bears high interest due to its uniqueness. The handbook was originally written with the aim of transmitting his knowledge to his elder son, for the latter to succeed Casola as a Royal Engineer. However, Casola's premature death provoked the handbook to be given a wider use as other students gained access to the text.

Keywords: Strongholds, Perspective, Paleography, Handwritten, Canary Islands, History.

\section{INTRODUCCIÓN}

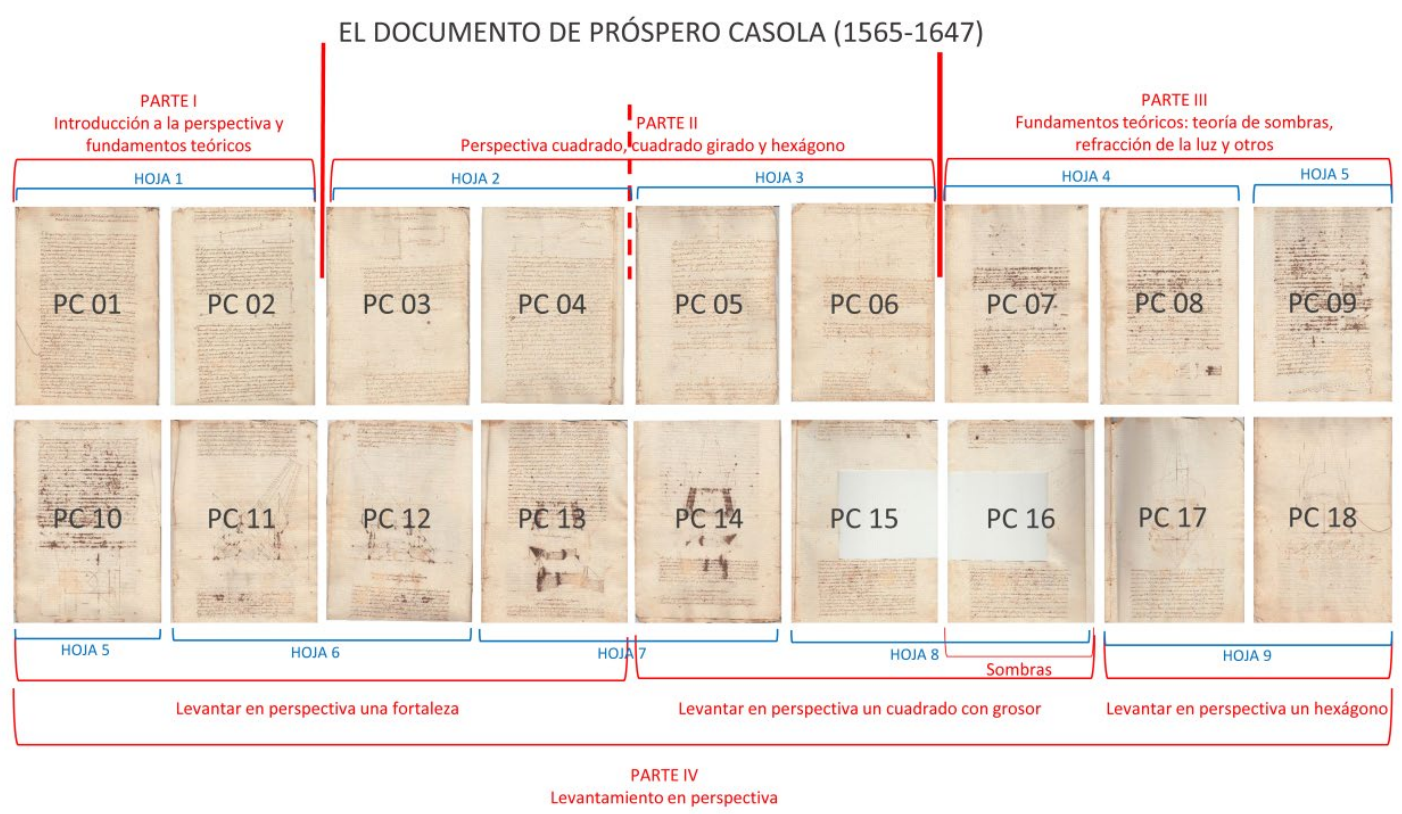

Figura 1. Documento completo, datos de identificación y divisiones propuestas.

Fuente Archivo Casa Condal de la Vega Grande y notas y elaboraciones propias.

El pequeño manual sobre el aprendizaje de la Construcción en Perspectiva que realiza Próspero Casola es uno de los trabajos más singulares en el contexto canario realizados en su época. El ingeniero italiano fue un técnico que con solvencia profesional mantuvo una preocupación constante por las fortificaciones de Canarias en general y especialmente por las de Gran Canaria, pues padeció, como testigo presencial, los ataques efectuados contra la ciudad de Las Palmas por los piratas Francis Drake (1595) y Pieter Van der Does (1599). De esta última incursión Casola realizó una relación que fue considerada por el profesor Rumeu de Armas, aún sin conocer su autoría, como una de las más fidedignas que se hicieron sobre aquel acontecimiento.

Próspero Casola tenía el privilegio de comunicarse personal y directamente con el rey, lo que entonces era prerrogativa de los ingenieros de la Monarquía, de ahí que pudiera interpretarse como obsesión la persistencia en el envío de cartas y misivas a los monarcas, en las que contaba todas las necesidades y vicisitudes de las fortificaciones canarias. Lo concerniente a su empleo solía transmitirlo oportunamente al Consejo de Guerra y a los propios reyes: Felipe II, Felipe III y Felipe IV ${ }^{1}$, ya que fue coetáneo de los tres debido a su longevidad; también mostró interés por otros temas relacionados con su profesión y con sus aficiones personales, de ahí que el italiano redactara algunos textos sobre la genealogía de la Casa de Austria o sobre las propiedades minerales de las piedras, así como el manual que aquí se estudia.

Todos estos documentos se conservan en el Archivo de la Casa Condal de la Vega Grande, en una carpeta denominada Próspero Casola. Es necesaria la paleografía para acceder a la

1 LOBO CABRERA Y BRUQUETAS DE CASTRO (1994). En esta obra se encuentra recogida y transcrita la correspondencia que el ingeniero mantuvo con los reyes de la Casa de Austria a lo largo de los años que permaneció en Canarias como ingeniero de la monarquía. 
transcripción de dichos manuscritos, que han sido realizados con letra pequeña, casi nimia, en pliegos de papel que se han deteriorado por el paso del tiempo, lo que dificulta aún más su lectura. La llegada de esta documentación a la familia Del Castillo se debe a los antojadizos vericuetos de la transmisión patrimonial debido a diferentes herencias, toda vez que la descendencia directa del ingeniero se truncó en la tercera generación, al morir su nieto sin herederos, por lo que la familia condal Del Castillo heredó las propiedades de Próspero Casola a través de doña Jerónima del Castillo Cabeza de Vaca, esposa de don Pedro Agustín del Castillo, padres del primer conde de la Vega Grande.

Algunos de los legajos de este corpus documental fueron utilizados por don Pedro Agustín del Castillo Ruiz de Vergara, quien se inspiró en esta fuente gráfica para la realización de sus libros. Esta es la razón que explica por qué el pequeño manual de perspectiva tenía, después de haber sido cosido, las hojas trocadas y algunas fuera de lugar, lo que obligó a hacer una revisión a fondo del texto hasta conseguir que cuadrara el discurso con los dibujos. Ahora creemos que el motivo por el cual Próspero Casola elaboró este pequeño manual se debió a su interés personal por transmitir los conocimientos técnicos que poseía para convertirlo en un modelo didáctico para instruir a alguien próximo: en un primer momento había pensado en su hijo mayor, también llamado Próspero, nacido en abril de 1607,al que aleccionó convenientemente en estudios de matemáticas y geometría, al que le aportó instrucciones específicas sobre la materia constructiva después incluso de que culminase sus estudios como ingeniero. El empeño de Próspero era que su hijo mayor le sucediera como ingeniero en la plaza de Canarias y así aparece reflejado en su primer testamento:

... a mi hijo he enseñado mi arte para que continúe esta fortificación, suplico a su magestad le haga merçed de confirmarle el dicho mi officio en pago a mis servicios, pues es hábil y suficiente para él con lo qual podrá sustentar a su madre y poner en estado a tres hijas que dejo doncellas ${ }^{2}$.

Sin embargo, la muerte prematura del vástago le sorprendió, lo que le obligó a poner por escrito parte de esta ciencia para su transmisión a otros jóvenes que también consideraba idóneos (tanto para el asunto profesional de la ingeniería militar y civil, como para convertirse en miembros de su propia familia). Ese fue el caso de los aspirantes a contraer matrimonio con sus herederas. Así, en dos ocasiones se dirigió al rey Felipe IV sobre este asunto. En una de ellas el aspirante se llamaba Pedro, joven mancebo, hábil y suficiente, que podría casar con una de sus hijas. Al fallarle dicho pretendiente pensó sustituirle por Francisco de la Puerta, una vez que se hubiese casado con una de sus hijas, pues era una persona de letras e inclinada a las matemáticas y a la geometría, hábil y con suficiente ingenio para dicho arte. Y finalmente el candidato fue el maestre mayor de la catedral Juan Lucero, por ser persona práctica y experimentada, con lo cual se aligeraría la construcción de las obras que aún quedaban pendientes en 1641 y con el tiempo quedaría provista una nueva plaza de ingeniero en la isla.

\section{Próspero Casola (1565-1647)}

Debe tenerse en cuenta que Prospero Casola, ingeniero militar al servicio de Felipe II, llegó a Canarias de la mano de otro compatriota, Leonardo Torriani, al que acompañó como su ayudante por comisión real. La elección de este vino motivada porque en aquel momento los ingenieros solo recibían su formación profesional de manos directas de otros ingenieros que ya hubiesen demostrado su pericia y práctica al servicio de la monarquía, como era el caso de Spanoqui. No fue hasta finales del siglo XVI cuando en Madrid se creó la primera academia de ingenieros, al estilo de la de Milán, y con profesorado mayoritariamente de origen italiano.

Próspero Casola había estado trabajando en el taller de Spanoqui desde muy joven; y había realizado los planos de Madrid junto con Torriani; por lo tanto, reunía todos los requisitos para que en el futuro pudiera convertirse en un buen ingeniero, como así sucedió. Formado en las

2 Archivo Histórico Provincial de Las Palmas, Andrés Rosales, nº 958, fs. 354 r y ss. Testamento de Próspero Casola. 
ideas del Renacimiento, combinaba el conocimiento de la técnica arquitectónica, especialmente en todo lo relativo a las construcciones defensivas, a lo que unía ser un experto en tácticas y estrategias militares. A ello se unía su curiosidad por distintas cosas, tanto espirituales, religiosas como históricas y narrativas.

Fue un gran conocedor del arte de la guerra, tal como lo demostró en el ataque holandés a la ciudad de Las Palmas, ya que tenían amplios conocimientos de matemáticas (aritmética y geometría), que se combinaban con la preocupación autodidacta por la historia, la ciencia de la geografía y la composición de los materiales, pues de todo ello escribió y comentó, dando interesantes opiniones personales, en los estudios que realizó sobre la arquitectura concreta de algunos edificios y de la ingeniería general de las fortificaciones y problemas de capital Gran Canaria.

Sus conocimientos los empleó en Canarias, proponiendo a las más altas instancias distintos proyectos para fortificar las distintas islas y especialmente Gran Canaria, lugar donde fijó su residencia. Conocía a la perfección los entresijos de la defensa y la combinación física y estratégica para construir bien un baluarte o una muralla, así como los mejores materiales para su mantenimiento.

Escritor incansable era capaz de divagar sobre los principios de la geometría de Euclides como sobre los fenómenos atmosféricos o el paso de un cometa y sus consecuencias, a la vez que era capaz de descubrir cuál era el problema de los arenales que afectaban a la ciudad de Las Palmas o estudiar la genealogía de la familia reinante en España, los Austrias, como escribir poemas sobre la situación de las Islas e imitar al propio Bartolomé Cairasco, el más insigne poeta canario del Renacimiento.

Los primeros dibujos descriptivos conocidos en Canarias, con utilización de formatos en la representación, que son asimilables en los resultados a lo que conocemos como sistemas de representación, corresponden a los realizados por el ingeniero militar italiano Leonardo Torriani (1560-1628), que fue nombrado ingeniero del rey Felipe II en 1584; entre sus trabajos, destaca el referido a la descripción de las islas Canarias y sus asentamientos que reflejó en su obra Descripción e historia del reino de las Islas Canarias ${ }^{3}$ : en ella se plasman una serie de dibujos que fueron realizados alrededor de $1588^{4}$ los cuales conocemos por una serie de cartografías de amplia difusión en el ámbito local e internacional ${ }^{5}$ : en ellas se utilizan diversas técnicas de representación, soportadas sobre variados sistemas de convenciones, a veces cargados de simbolismos. Sin embargo, con anterioridad al documento que mostramos, no se ha conocido manual alguno para el aprendizaje de la representación en perspectiva.

Como se dijo antes, Próspero Casola llegó en compañía de Leonardo Torriani en 1587, reconociendo en sus informes haber sido discípulo también de los ingenieros Agustín Amodeo y de Tiburcio Espanoqui, activos en la planificación de fortalezas en el territorio canario: así Casola rápidamente se convirtió en experto conocedor de las fortificaciones en Canarias ${ }^{6}$.

El principal valor de este documento radica en que constituye un registro histórico que arroja luz en lo que pudo ser la forma de transmisión del conocimiento sobre la perspectiva en el archipiélago canario, a todas luces muy distante de lo que en el mismo periodo se estaba realizando en Europa, pues ya existen documentos desde 1413 relacionados con las perspectiva asociados a Brunelleschi ${ }^{7}$.Este manual probablemente estaba destinado a uso privado o como mínimo para la formación de un grupo específico, no disponible para el común, esto nos lo hace pensar el hecho de haberse mantenido desconocido hasta ahora y probablemente solapado posteriormente con la llegada de materiales innovadores procedentes de Europa, dado el carácter cosmopolita de los puertos canarios como lugares de tránsito de los buques hacia otros continentes y parada obligada para el suministro de todo tipo.

El dibujo en perspectiva es suficientemente conocido en la cultura europea durante los siglos XVI y XVII, por lo que su avance y desarrollo marca distancia con los materiales que describimos. Hacer una comparación de este manual con los tratados y materiales producidos

3 TORRIANI (1588).

4 MARTÍN GALÁN (1986).

5 SOLANA SUÁREZ (1994).

6 LOBO CABRERA Y BRUQUETAS DE CASTRO (1994).

7 KEMP (1994). 
con carácter análogo sobre perspectivas en el mismo periodo, sería un trabajo estéril en la medida en que el documento hallado se encuentra planteado en unos niveles muy básicos, más vinculado a la instrucción doméstica que a pretender un desarrollo cercano a un tratado. Por ello, hemos insistido en el análisis del documento a través de su descripción, análisis e interpretación, tratando de darle estructura y establecer sus antecedentes más probables, en los que se encuentran textos, dibujos y elementos alfanuméricos. Los textos se centran en la descripción y utilidad de lo gráfico, y lo gráfico viene acompañado de elementos alfanuméricos que son aclarados con las consiguientes explicaciones.

Próspero Casola nació en torno a 1565 en Reggio Emilia, en Lombardía, estado del duque de Módena, de acuerdo con sus propias declaraciones, pues en 1596 afirmaba tener treinta años; sus padres fueron Cosme Casola y María Lucrecia Crota, ambos naturales del mismo lugar, según declara en su testamento, cuya descendencia de padres y abuelos «dexo declarado en un libro pardo que queda en mi escritorio que por ser algo largo no lo pongo aquí» ${ }^{8}$.

Llegó a Gran Canaria en 1587 y su ascenso profesional se desarrolló con cierta rapidez y se mantuvo soltero hasta 1605 , año en que ( 7 de febrero) contrajo matrimonio en la iglesia parroquial de Telde con doña Isabel Imperial Zurita, natural de Telde, hija de Octaviano Imperial $^{9}$ y de doña Beatriz Díaz de Zurita ${ }^{10}$, por lo que entronca con una familia que tenía su origen en la conquista de la isla y que había enlazado con mercaderes genoveses. Los casó el bachiller Pedro González y fueron sus padrinos personas destacadas en la sociedad del momento, como el doctor don Francisco Mexía, deán y canónigo de la catedral, pariente de su mujer por la línea de los Castillo, a quien llama tío, Hernando del Castillo, Lorenzo de Zurita y otros muchos ${ }^{11}$.

El matrimonio tuvo seis hijos: dos hombres y cuatro mujeres, nacidos en Las Palmas y bautizados todos en la iglesia del Sagrario, de los cuales solo le sobrevivieron cuatro. Estos fueron Beatriz, que tomó el nombre de su abuela, bautizada en 15 de febrero de 1606, cuyo padrino fue el prior y canónigo de la catedral don Bartolomé Cairasco de Figueroa, la cual falleció; el 27 de abril de 1607 recibió el agua del bautismo su hijo Próspero, actuando como padrino el capitán y gobernador don Luis de Mendoza; su hija María fue bautizada igualmente en el Sagrario el 24 de agosto de 1609, apadrinada por el regidor don Alonso de Olivares; dos años más tarde, el 2 de diciembre de 1611, era bautizada su hija Beatriz, cuyo padrino fue el receptor del Santo Oficio don Lorenzo de Zurita; el 18 de marzo de 1615 fue bautizado su hijo Cosme, llamado como su abuelo paterno, y cuyo padrino fue el chantre de la catedral don Juan Sotelo, el cual asimismo falleció con posterioridad, finalmente, su hija Isabel, nacida el 9 de mayo de 1620, fue bautizada el 26 de mayo y cuyo padrino fue el señor doctor don Juan Francisco Mexía, deán y canónigo de la catedral ${ }^{12}$. A través de estas partidas y de los apadrinamientos de sus hijos se puede comprobar el círculo de amistades en el cual se movía el ingeniero italiano.

En Las Palmas compró una casa en el barrio de Triana, que la incendió el holandés con todo lo que había dentro, razón por la cual en 1603, al no haber podido restaurarla, reclamó al rey se le diera alojamiento, porque después de haber estado sirviendo a la Corona más de catorce años no se le había dado vivienda. Después de casado vivió en esa casa, que había comprado a Marcos de León en 55 doblas. Estaba ubicada en el barrio de Triana, en la calle de los Remedios, lindando con casas de Francisco Gutiérrez de Ávila, con otras que fueron de Pedro del Castillo y con las del deán y canónigo del catedral don Francisco Mexía. Consiguió tener asiento en el cabildo como regidor, en la vacante producida por el fallecimiento de Francisco de

8 Testamento otorgado por Próspero Casola en 9 de diciembre de 1629. Archivo Histórico Provincial de Las Palmas, Andrés de Rosales, no 958, f. 354 y ss.

9 Era hijo de Juan Bautista Imperial y María Cerezo, y tuvo como hermanos a Ana Imperial y a Melchor Imperial.

10 Era hija de Isabel Hernández Zurita y de Diego Díaz, por tanto, nieta del conquistador Bartolomé Martín de Zurita y de María Fernández Calva, patronos de la capilla de San Bartolomé de la iglesia de San Juan de Telde, y a su vez heredera de la capellanía que había fundado su abuela sobre la Hoya llamada de María Fernández Calva, y luego de Próspero.

11 Archivo Parroquial de San Juan de Telde, Libro $1^{\circ}$ de matrimonios, fs. 47 v. -48 r.

12 Archivo Diocesano de Las Palmas, Libro $6^{\circ}$ de bautizos del Sagrario, fs. 325 r., 362 v., 426 v. y 487 r. y Libro $7^{\circ}$ fs. 69 r. y 257 v. 
la Mata. Le fue despachado el título de regidor con carácter vitalicio en 1610, mediante despacho del rey Felipe III fechado en Valladolid en 3 de abril, y tomó posesión en el cabildo de Gran Canaria el 9 de julio ante el gobernador de la isla don Luis de Mendoza y Salazar.

Después del ataque holandés su actividad como ingeniero fue mucho más intensa en las Islas, ya que durante dieciocho años combinó sus labores con la de contador y veedor de la gente de guerra, obras y fortificaciones, por lo que tuvo que viajar por todas las Islas y realizar diversos informes sobre su estado de defensa. En 1632 emprendió en Gran Canaria la obra del castillo de Santa Catalina (donde hoy se encuentra la base naval), imprescindible para defender aquella zona de los desembarcos enemigos. Otro hito importante fue la restructuración del castillo de la luz en la Isleta y las reformas de los baluartes costeros de la ciudad de Canaria: Santa Ana, Buen Aire, San Fernando, San Felipe, San Antonio, Santa Isabel y San Pedro y, por último las murallas de la ciudad, el baluarte de Mata y el fuerte de San Francisco o castillo del Rey ${ }^{13}$.

Cerca ya de su muerte fue nombrado corregidor de ausencias en 1645 como reconocimiento al gran prestigio alcanzado en la ciudad. Falleció en Las Palmas el 6 de junio 1647 a los 82 años de edad. Sus restos fueron inhumados en la capilla mayor del convento de San Francisco de Las Palmas, en la sepultura que allí tenía, donde había sido enterrada su mujer.

\section{DESCRIPCIÓN, ANÁLISIS E INTERPRETACIÓN DEL DOCUMENTO}

Para apoyar el trabajo paleográfico realizado, ha sido necesario revisar los dibujos del documento que referimos, donde en un primer acercamiento se deduce que existen hojas trastocadas y fuera de lugar como consecuencia de incoherencias técnicas registradas y también en la organización formal del documento que más adelante pasaremos a mencionar.

En lo referente a las incoherencias técnicas es necesario mencionar que, tal como se presenta la secuencia de gráficos y textos, hacía incomprensible técnicamente el documento. La búsqueda de elementos que dieran coherencia formal al manuscrito ha hecho posible identificar que se trataba de dos legajos intercalados. La identificación de las transferencias de dibujos de una página a otra y la diferente forma de presentación ha facilitado dicho trabajo. Así mismo, estas páginas intercaladas, con la doble lectura de algunos elementos alfanuméricos, hacían que las explicaciones técnicas no se correspondieran. Solo al ordenar el documento y relacionar las explicaciones técnicas con sus dibujos, es cuando se clarifican las lecturas de los signos que le acompañan. No es necesario comparar con otros estudios paleográficos: el documento técnico que se nos presenta no admite otra explicación científica que la respuesta propuesta.

Al referirnos a su contenido, con el fin de facilitar la comprensión, cuando hacemos alusión a una página, referirá el orden en que se encuentran encuadernadas en el manuscrito original y que servirá de referencia para hilar y ordenar el discurso analítico pretendido. Por otra parte, puede ser tentador, a la vez que pretencioso, tratar de hacer un paralelo entre este documento y los tratados que sobre perspectiva existen en la Italia del siglo XVII; sin embargo, habiendo sido una intención inicial la mera revisión de los documentos de estas características, nos ha hecho desechar tal propósito, por cuanto la distancia existente entre nuestro documento, de perfil muy doméstico, y la cualidad de los mencionados tratados obligan a reconocer el interés local que se desprende como documento contextualizado en una sociedad con un desarrollo vinculado a procesos coloniales de culturización, por debajo de los aportes que el desarrollo de la perspectiva en profundidad disponen en el contexto internacional.

La sistematización de la perspectiva permitió el acceso a la representación tridimensional de una forma técnica sin exigir grandes destrezas gráficas, de tal manera que desde el ámbito de las ingenierías se accede a su utilización sin necesariamente vincularse al mundo de la pintura y las artes en general donde mantuvo una importante proyección. Por tanto el interés de la aportación del presente artículo es dejar registro de la forma descriptiva en que este primer manual aparece

13 Algunos desaparecieron o cambiaron de denominación y de lugar con el tiempo, como sucedió con el baluarte de San Felipe o el torreón de San Pedro, también conocido como de San Cristóbal. La construcción de estos se debía al gobernador Rodrigo Manrique de Acuña, quien la ordenó en 1544; pero todos sucumbieron en poco tiempo, aunque su ubicación era la idónea. 
en Canarias de la mano del ingeniero Próspero Casola, enfatizando que su valor radica en la singularidad que significa la inexistencia de referentes anteriores en el contexto local de las islas Canarias. Por ello pasaremos a su descripción, acompañado de algunas imágenes, al tiempo que resulta necesario ordenarlo, pues debe persistir la coherencia técnica y formal para poder estimar la condición original presentada por su autor.

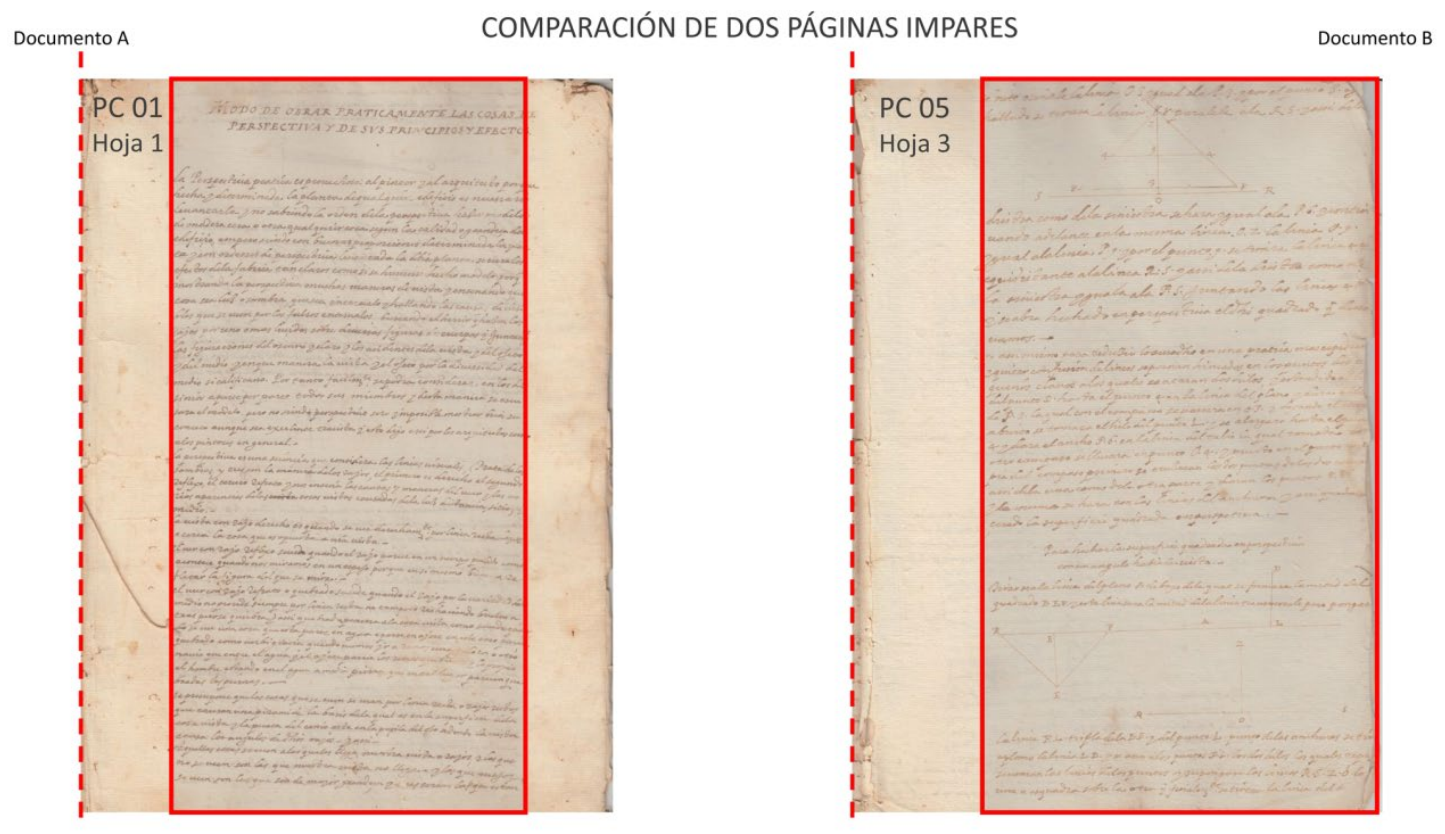

Figura 2. Comparación tipos de páginas impares.

Fuente Archivo Casa Condal de la Vega Grande y notas y elaboraciones propias.

El documento elaborado por el ingeniero militar Próspero Casola Cota (1565-1647) se compone de nueve hojas cosidas, con dibujos, textos y elementos alfanuméricos, y el lenguaje de su expresión escrita es lo que conocemos como castellano antiguo. Su título, recogido en su encabezamiento, «MODO DE OBRAR PRATICAMENTE LAS COSAS DE PERSPECTIVA Y DE SUS PRINCIPIOS Y EFECTOS» Carece de portada, y en sus contenidos se combinan, como se indicó, textos, dibujos y expresiones alfanuméricas. Todas las hojas están tratadas por ambas caras, con elementos de las características que significa un documento compuesto por un total de dieciocho páginas.

Como complemento a la descripción general, es preciso añadir que la utilización de la doble cara en cada hoja para aportar contenidos ha generado transferencia de tinta a la página adyacente, por lo que se produce confusión para su lectura y comprensión, ejemplo de ello son las páginas trece y catorce, situadas en la hoja número siete del documento. Igualmente, parece de interés señalar, para completar la descripción que se pretende, que la hoja número ocho está mutilada por causa del recorte de su zona central, donde se estima, siguiendo la lógica de la construcción del documento, debería encontrarse dispuesto, un dibujo relativo a la información descriptiva que realiza el autor. 


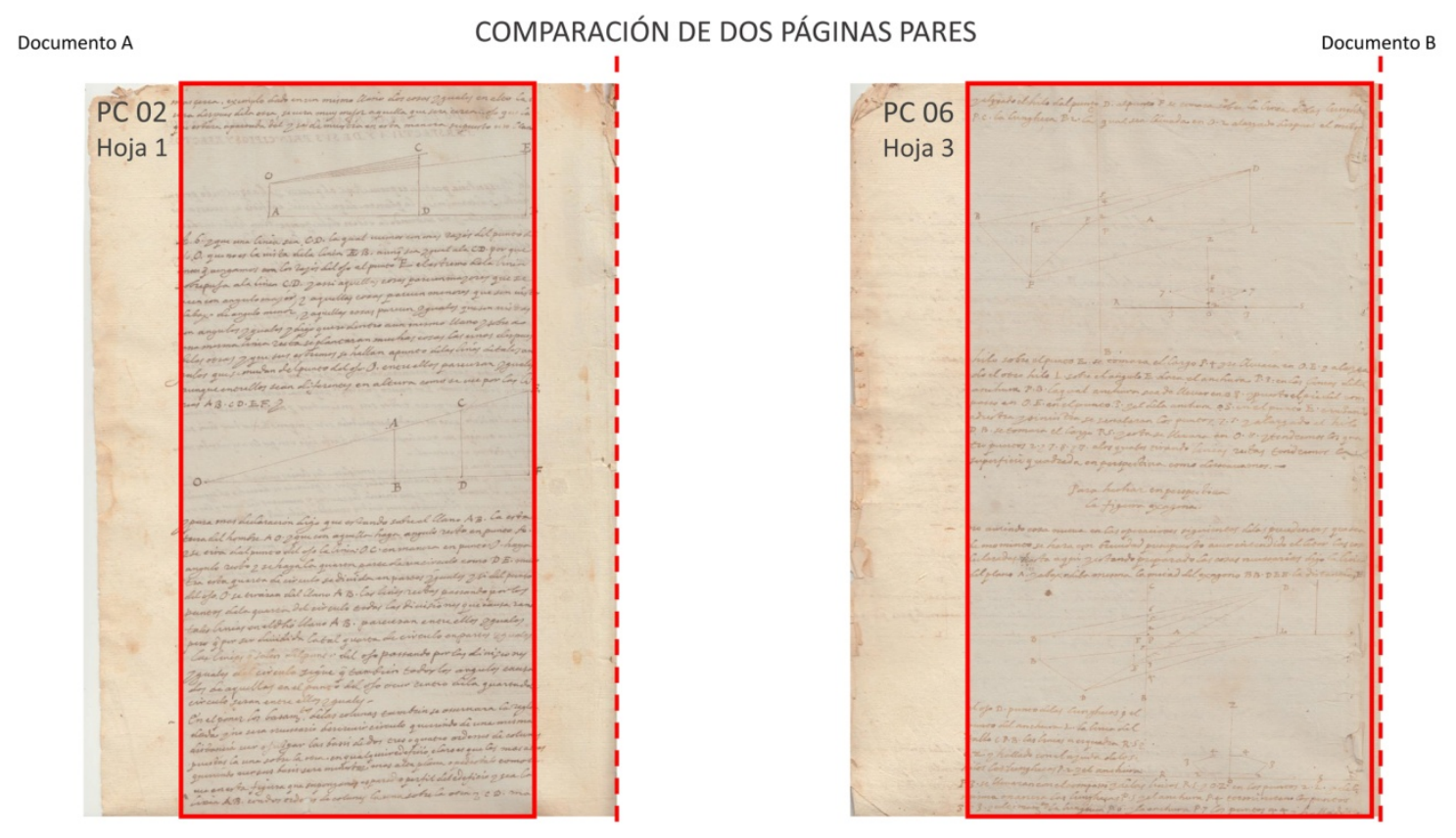

Figura 3. Comparación tipos de páginas pares.

Fuente Archivo Casa Condal de la Vega Grande y notas y elaboraciones propias.

En la organización de los textos y símbolos alfanuméricos, así como los dibujos en cada una de las páginas, destacamos dos tipos a partir de sus posiciones. Un primero, presentados en la hoja número uno y en las seis últimas del documento original. En ellas, su composición y justificación queda centrada en la página, dejando márgenes iguales a derecha e izquierda. El segundo tipo está presente tan sólo en dos hojas, la número dos y tres: en este, se caracteriza por la alineación del texto hacia uno de los bordes de la página, dejando un importante margen en el otro extremo. El margen se presenta siempre dispuesto a la izquierda de los textos y, como consecuencia, su alienación se produce hacia el exterior en la página en las impares y hacia el interior en las pares, donde se produce su cosido.

En la primera transcripción paleográfica que se realiza del documento, una de las dificultades presentes se refiere a las descripciones que el autor realiza de los dibujos. Se confunde con facilidad la letra $S$ con el número 5 ; la letra $Z$ con el número 2 o el 3 y el 8 ; una vez interpretada la significación técnica del contenido documental, es posible ajustar su verdadera acepción, pues no es un sistema codificado universal que permita una equivalencia semántica aplicable en todos los casos de trabajos en paleografía: es a partir de la lógica técnica de los contenidos, lo que permite interpretar correctamente estos elementos alfanuméricos, en cuya confusión coadyuva la rotulación a mano alzada del autor que introduce elementos de personalidad en el trazo de tales referencias. Es a través de un proceso de traducción, relectura y nueva interpretación de los contenidos técnicos, que tales significados son clarificados y ajustados. 


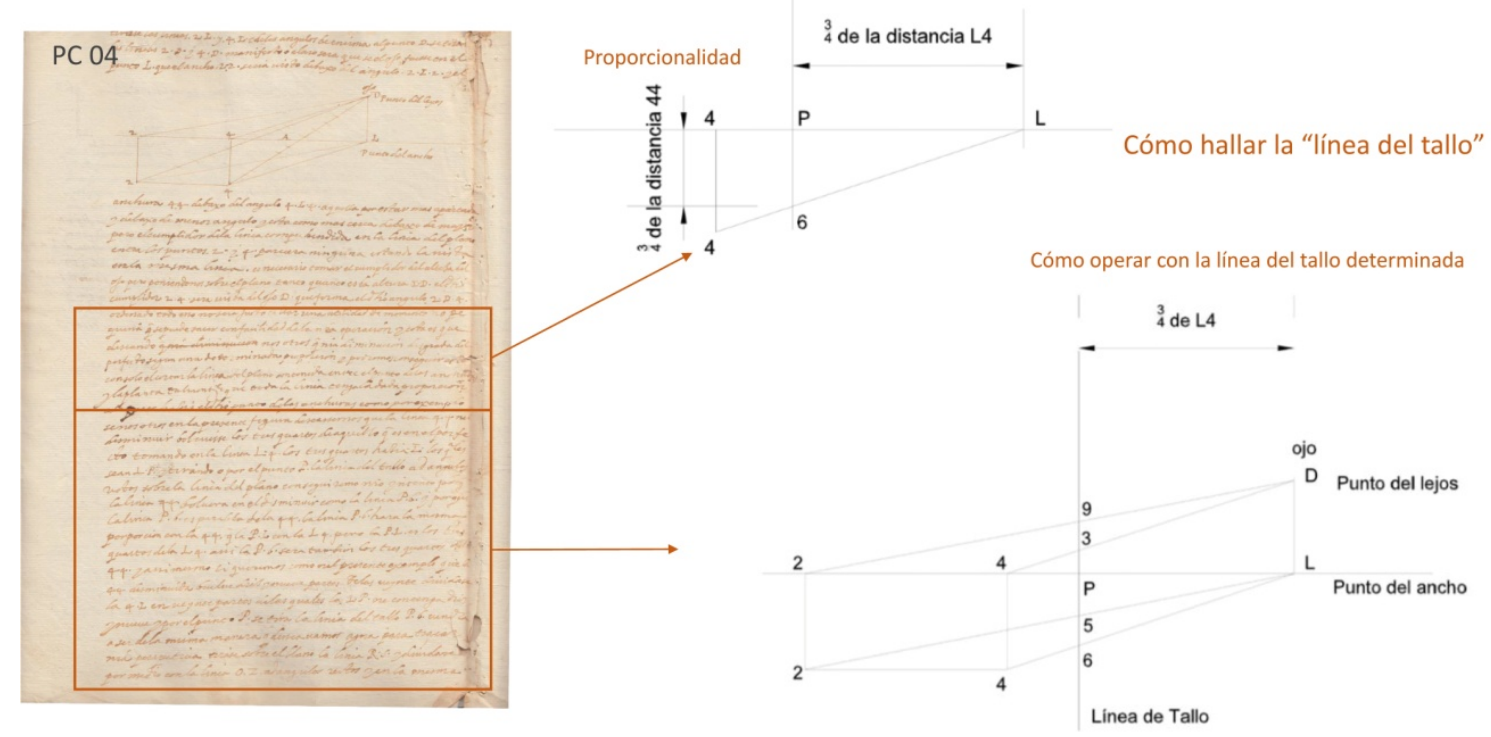

Figura 4. Análisis de contenidos para paleografía.

Fuente Archivo Casa Condal de la Vega Grande y notas y elaboraciones propias.

Tras varias lecturas, traducciones, interpretaciones y revisiones del manuscrito, determinamos la siguiente estructura original que hace coherente su construcción y contenidos técnicos, poniendo de manifiesto el error de agrupamiento final producido en la secuencia de sus hojas, probablemente realizado con posterioridad a su autoría con el deseo de impedir su pérdida por disgregación. De esta forma se puede esbozar un índice a partir de las correspondientes temáticas:

Parte I: Introducción al tema de la perspectiva y sus fundamentos (página 1 y 2).

Parte II: Perspectivas de polígonos en dos dimensiones en diversas posiciones: cuadrado, cuadrado girado y hexágono (páginas $3,4,5$ y 6 ).

Parte III: Fundamentos teóricos sobre la construcción geométrica de la perspectiva; de igualmente se añaden diversos aspectos vinculados como la refracción de la luz y producción de sombras (páginas 7, 8 y 9) y su forma de representación gráfica.

Parte IV: Levantamiento (construcción gráfica) de figuras usando la geometría de la perspectiva, aplicado a modelos específicos: fortaleza amurallada, cubo hueco con espesor en sus bordes y prisma de base hexagonal: todos estos elementos dispuestos en las últimas nueve páginas del documento original.

Otra característica que resalta en la construcción del documento a través de sus contenidos es la relativa a los saltos existentes dentro de los desarrollos expuestos en las partes I y II, y la II y III, pues resulta que la parte II se encuentra aislada del discurso general. Esto adquiere mayor coherencia, cuando la morfología y estructura interna de las páginas se hacen coincidentes, interpretación que se confirma cuando se verifica que los textos que describen contenidos en la página segundase refieren técnicamente a los dibujos contenidos en la página séptima. Por otra parte y para mayor confirmación, los contenidos tratados en la parte III, el rayo refreto y la sombra, son identificados al final de la parte I: «la perspectiva es una ciencia que considera las líneas visuales, trata de las sombras y tres son las maneras de los rayos, el primero es derecho, el segundo reflexo, el tercero refrato...» (p. 2). Por todo ello, estamos en condiciones de afirmar que las hojas número dos y número tres, en lo que se refiere a su localización, no se corresponden con el lugar que ocupan en el documento original encuadernado, por lo que podemos ser categóricos en que el documento original contiene dos partes bien diferenciadas, si bien ambas relacionadas con la metodología para el aprendizaje de la construcción geométrica de la perspectiva. 


\section{LOS DIBUJOS RECORTADOS DEL DOCUMENTO (HOJA 8)}

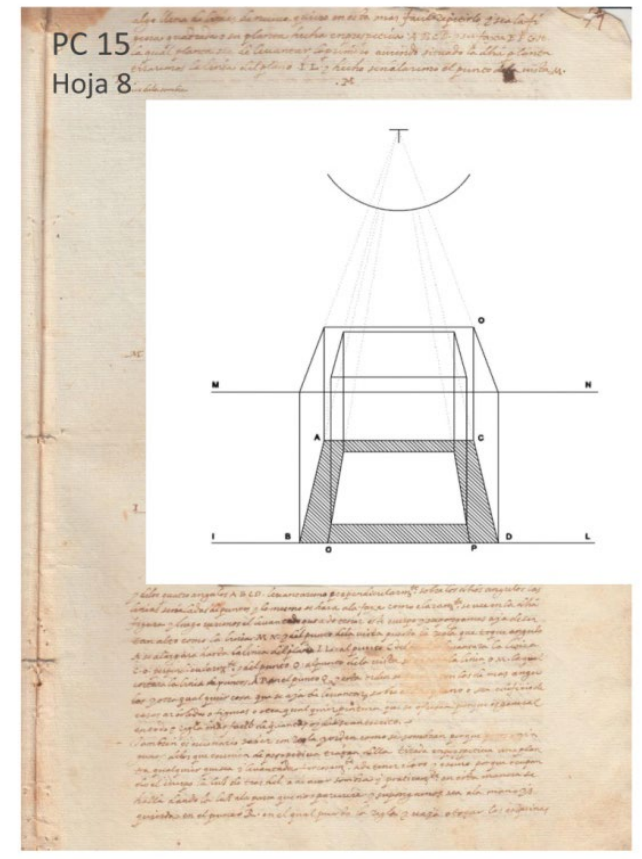

Figura 5. Dibujos recortados del documento, reconstrucción. Fuente Archivo Casa Condal de la Vega Grande y notas y elaboraciones propias.

Como consecuencia de lo anteriormente expuesto, podemos confirmar la afirmación realizada relativa a que el documento fue reordenado alterando la estructura original de sus páginas, probablemente como consecuencia de haber encontrado desordenadas y trastocadas las hojas que componen el documento, pues se había reagrupado de buena fe, con el mejor criterio disponible. Afirmamos por tanto, que la parte documental que hemos nominado como parte II forma parte de un conjunto documental independiente, fundamentado en aspectos como la forma de expresión escrita, y la secuencia de aplicación del método para la construcción geométrica de la perspectiva que incluye. El resto del documento viene conformado por las secciones que hemos denominado parte I, parte III y parte IV.

De esta forma, la estructura definitiva que proponemos es la siguiente:

\section{Documento A:}

Formado por la hoja número uno y las hojas desde la número cuatro hasta el final del documento, lo que hace un total de siete, diferenciadas, en cuanto a contenidos, de la siguiente manera:

Parte I: Introducción al tema de la perspectiva y sus fundamentos, que ocupa las cinco primeras páginas.

Parte II: Levantamiento (construcción) de figuras con perspectiva geométrica, que se representan en tres dimensiones (fortaleza, cubo hueco con espesor y prisma de base hexagonal) que comprenden las últimas nueve páginas.

\section{Documento B:}

Las hojas nominadas como número dos y número tres constituyen un documento independiente, tal vez pueda formar parte de otra documentación de mayor tamaño, y que trataría sobre la construcción de la perspectiva geométrica aplicada a polígonos (cuadrado, cuadrado girado y hexágono). Por otra parte, como desarrollamos más adelante, el método aplicado la para la construcción geométrica de las perspectivas de estos elementos difiere del que ha sido empleado para el resto del documento original. 


\section{El documento A}

Como ya se ha descrito, viene configurado por dos secciones bien diferenciadas: la correspondiente con introducción y fundamentos del sistema de representación, y la que muestra como se realiza la construcción gráfica de las piezas en tres dimensiones.

En la introducción Próspero asevera que se trata de un manual práctico «la perspectiva práctica es provechosa al pintor y al arquitecto» no haciendo cita alguna a los autores italianos que han descrito con profusión estos asuntos. Así mismo, recuerda que «la perspectiva es una sciencia que considera las líneas visuales, trata de las sombras y tres son la manera de los rayos, el primero es derecho, el segundo reflexo, el tercero refrato...» (p. 1). A lo largo de las cinco primeras páginas desarrollará todas estas cuestiones.

De las figuras tridimensionales, construidas en perspectiva, fortaleza, cubo hueco y prisma hexagonal, podemos afirmar que representación de la fortaleza se acomete con la intención de proporcionar un caso de aplicación general; y los otros dos casos, el cubo hueco con espesor y el prisma hexagonal, se utilizan para explicarla aplicación a casos características específicas y particulares, alineando las figuras con el plano del cuadro, para buscar una más fácil comprensión.

En el caso general, la figura se sitúa perpendicular al plano del cuadro y tangente a él en los vértices de los baluartes. Para la realización de la perspectiva, Próspero dibuja los siguientes elementos: la línea $\mathrm{AB}$, , identificada como «orizontal del plano» (p. 11) o «línea del plano» (p. 12), que es la intersección del plano donde se sitúa la fortaleza con el plano sobre el que se va a representar, lo que actualmente identificamos como línea de tierra; el punto de vista, que aparece identificado por el dibujo de un ojo y por el punto $\mathrm{C}$, que es el punto al que se fugan las rectas perpendiculares al plano de representación, (obsérvese que el punto de vista se encuentra desplazado con respecto a la figura y esto permitirá en su representación final que la fortaleza se vea una de las caras laterales) $\mathrm{y}$; por último, el punto $\mathrm{D}$, que será el punto de medida o distancia accidental, punto de apoyo para medir en perspectiva, lo que conocemos por la distancia que existe entre punto de vista al plano de representación y que Próspero define como «la distancia apartada a la cosa de la voluntad del que quisiere obrar» (que en geometría identificamos como el delta de medida de las rectas perpendiculares al plano del cuadro, punto de fuga de la rectas que forman cuarenta y cinco grados con el plano del cuadro).

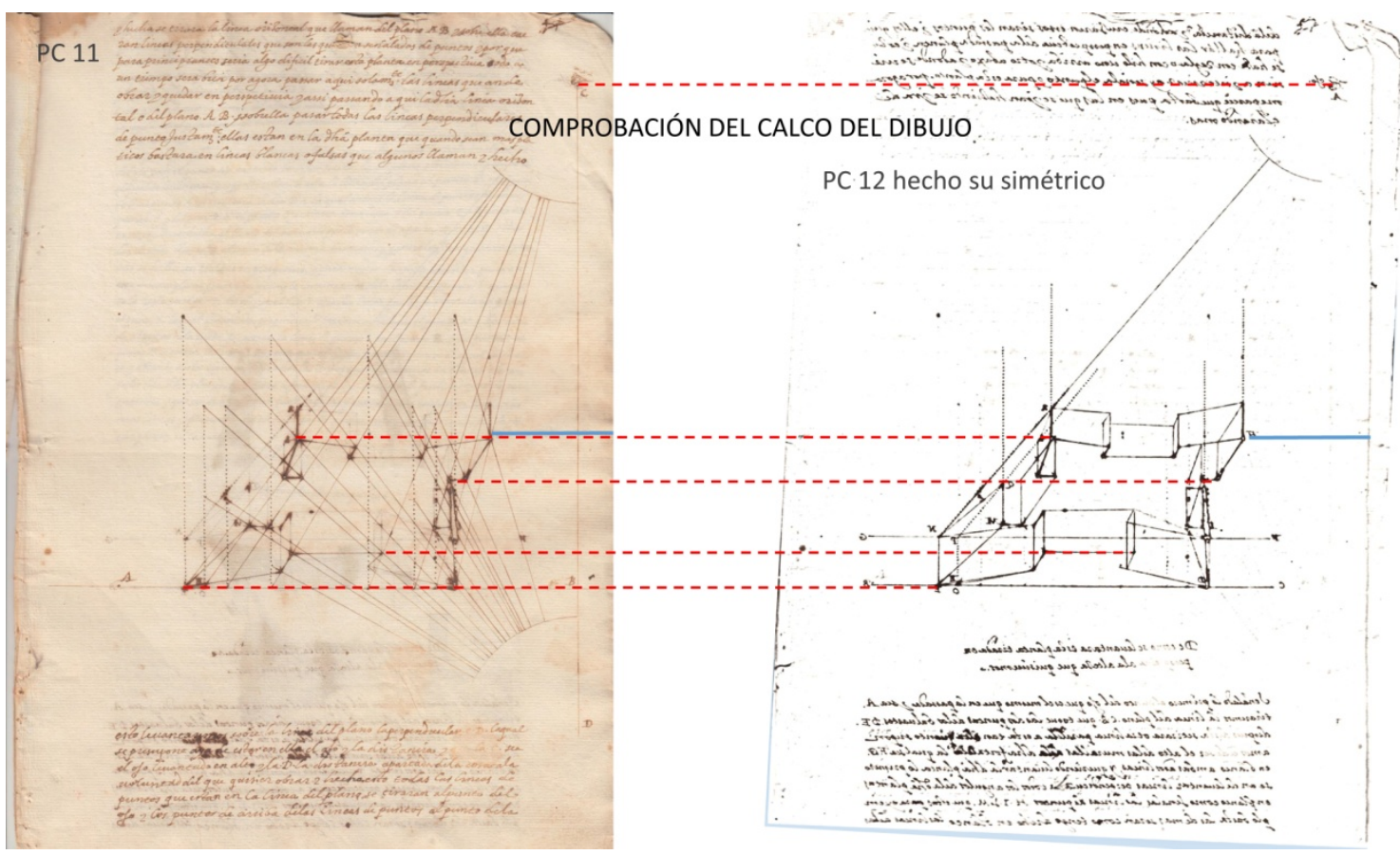

Figura 6. Comprobación de calco en los dibujos.

Fuente Archivo Casa Condal de la Vega Grande y notas y elaboraciones propias. 
Es preciso señalar que los dibujos que se encuentran en las páginas once y doce del documento son simétricos. Planteamos como hipótesis que Próspero de Casola realiza el dibujo de la cara impar de la hoja, y el de la cara par es el resultado de copiar por transparencia el primero, facilitado por lo traslúcido del gramaje del papel. Este hecho le facilita el trabajo por la rapidez de su ejecución manteniendo una mayor claridad visual, sin modificar la referencia. Como resultado, ambos dibujos, mantienen simetría con respecto al eje que marca la línea de cosido del documento.

En el proceso del levantamiento de las alturas de la fortaleza, se empezará por las situadas en el plano del cuadro, plano vertical de proyección, que coinciden con los dos puntos de tangencia de los baluartes con la línea denominada en el dibujo CB y que tienen por característica, conservar su verdadera magnitud, es decir, la dimensión en el dibujo coincide en escala con la dimensión real.

Para el dibujo situado en la siguiente hoja, página trece, donde aparece la fortaleza levantada y sombreada, también mantenemos la hipótesis de que es copiado por transparencia, calco del realizado en la página anterior, ya que mantiene el mismo tamaño, forma y proporción. En este caso, al estar en diferente hoja, la relación del dibujo con los márgenes es distinta.

En el caso del cubo con grosor y hueco, la perspectiva se ha realizado ubicando al observador centrado con respecto a la figura. El modo de proceder para levantar en perspectiva la figura es el mismo que el seguido para la fortaleza. Se da el caso que los dibujos correspondientes para levantar la altura de la figura y hallar su sombra, se encuentran recortados de la hoja. Hemos transcrito el dibujo del cubo con las alturas, siguiendo las indicaciones del texto y la lógica de la perspectiva.

El caso particular del hexágono, donde este se coloca de tal forma que solo un vértice está en el plano del cuadro, coincidente con el eje central del dibujo, trata de explicar cómo levantar las alturas de la figura cuando el observador se ubica centrado con respecto a la figura, coincidiendo su posición con una de sus alturas, lo que en términos geométricos implica que las líneas son coincidentes con la que une el punto de vista y el delta de medida (punto de medida).

\section{El documento B}

Como hemos visto, está configurado tan solo por dos hojas. Aunque el texto mantiene continuidad en el discurso, planteamos como hipótesis que faltan dibujos previos a los existentes en la segunda hoja de este apartado. Esta hipótesis se sostiene tras la lectura de las nueve hojas que conforman el documento original. Todos los dibujos que aparecen en él llevan una descripción precisa de sus elementos. Detectamos que al final de la segunda hoja, se hace una descripción exhaustiva de un dibujo, con números, letras y elementos alfanuméricos, el cual no se refleja gráficamente, y que hemos podido redibujar a partir de las indicaciones expresadas en ella. Este dibujo trata sobre la forma de hallar la «línea del tallo» (lo que actualmente asociamos al plano del cuadro, al plano donde se realizan las representaciones) dependiendo del tamaño en que se proponga visualizar la perspectiva de la figura.

Los dibujos en esta parte del documento explican la manera de obtener los anchos y las profundidades. Ambas dimensiones son obtenidas a partir de un mismo dibujo. La manera en que se obtienen las profundidades es asimilable a la representación de la visión transversal de los elementos de la perspectiva cónica, conocida como tercera proyección o proyección sobre un plano de perfil, donde representamos el plano del suelo (identificado como la línea PL), el plano del cuadro o, como Próspero Casola lo llama, «línea del tallo» (identificado como la línea CPB) y el punto de vista (identificado en el punto D). La manera de obtener las medidas de los anchos es trabajar con el círculo de medida de las rectas perpendiculares al plano del cuadro, tomando de este el punto que se encuentra en la inferior de la vertical. Una vez obtenidos los anchos y profundidades, Próspero se vale de una construcción auxiliar para llevarlas y obtener la perspectiva de las figuras. La particularidad en todas ellas es que el observador se encuentra en el punto medio de la figura. 


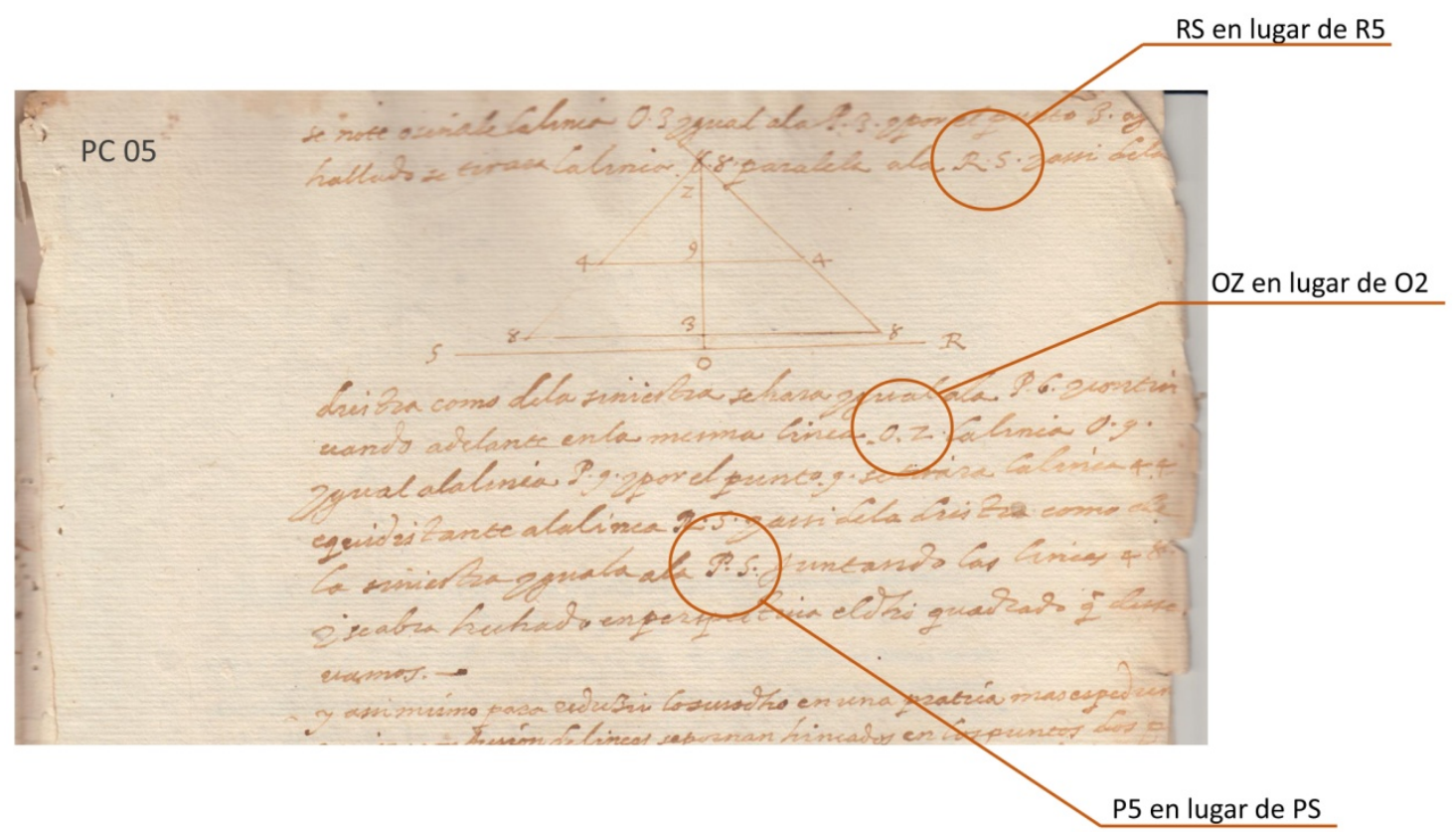

Figura 7. Ajustes de erratas en la paleografía.

Fuente Archivo Casa Condal de la Vega Grande y notas y elaboraciones propias.

\section{CONCLUSIONES GENERALES.}

Este hallazgo aporta un documento inédito que permite conocer el momento en que se encuentra en Canarias sobre el desarrollo técnico en la construcción geométrica de la perspectiva.

Este material con temática específica es el más antiguo conocido en el ámbito local de Canarias, aproximando las fechas en que se elaboran estos manuales; si bien no queda clara la designación de sus destinatarios y, por tanto, la proyección final que tiene hacia su publicación.

Podemos afirmar que a partir de la llegada de Leonardo Torriani, y los trabajos de Próspero Casola, el imaginario gráfico en Canarias se transforma.

La presencia de ingenieros italianos incorpora una forma de expresión que se fundirá en el imaginario colectivo de Canarias y el estilo de la representación gráfica local como fenómeno.

Quedarían por determinar las relaciones de este tipo de legajos con la creación de documentos cartográficos, y gráficos de otros orígenes, para determinar hasta dónde tiene influencia en la descripción del tipo de representación producida en la cultura local, y de qué manera se han venido desarrollando y complementando.

\section{CONCLUSIONES DEDUCIDAS DEL DOCUMENTO}

El documento ha sido reordenado y recosido, con errores en la secuencia relativa de sus páginas.

El documento obtenido se configura realmente por dos manuscritos independientes, diferenciados en la forma de escritura, formato de presentación, contenidos y metodologías que proponen para la construcción perspectiva.

Al manuscrito identificado como documento $B$ le falta un dibujo descrito al final de la página cuatro, clave para entender cómo hallar la que denomina línea de tallo, según su m método y que posteriormente empleará en el resto de las representaciones.

Los dibujos que deberían aparecer en la hoja recortada serían el cubo hueco levantado en perspectiva con las alturas correspondientes y también realizado con sombras. 


\section{REFERENCIAS}

KEMP, M. (1994). La Scienza dell'Arte. Prospettiva e percezione visiva da Brunelleschi a Seurat.Fierenze: Giunti Gruppo Editoriale.

LOBO CABRERA, M. y BRUQUETAS DE CASTRO, F. (1994). El ingeniero militar Próspero Casola y Canarias (Escritos, informes y descripciones). Las Palmas de Gran Canaria: Cabildo Insular de Gran Canaria.

MARTÍN GALÁN, F. (1986). La primera imagen de Canarias. Los dibujos de Leonardo Torriani. Santa Cruz de Tenerife: Colegio Oficial de Arquitectos de Canarias.

SOLANA SUÁREZ, E. (1994). «La fortificación del Jardín de las Hespérides. Narración mítica frente a la descripción gráfica de Leonardo Torriani sobre Canarias». Revista Expresión Gráfica Arquitectónica EGA, Valladolid, núm. 2, pp. 110-114.

TORRIANI, L. (1588). Descripción e historia del reino de las Islas Canarias. Traducción, Santa Cruz de Tenerife: Goya Ediciones, Colección de Clásicos Canarios. 